Buana Sains Vol 17 No $1: 65$ - 74

\title{
KONSEP AKSESBILITAS DAN VEGETASI PADA TAMAN BERMAIN ANAK DIFABEL DI SLB-C LAWANG
}

\author{
Irawan Setyabudi $^{1}$, Wahidyanti Rahayu Hastutiningtyas ${ }^{2}$ dan Maria Nelde Olo $^{1}$ \\ ${ }^{1}$ Program Studi Arsitektur Lanskap, Fakultas Pertanian, Universitas Tribhuwana Tunggadewi \\ ${ }^{2}$ Program Studi Ilmu Keperawatan, Fakultas Ilmu Kesehatan, Universitas Tribhuwana Tunggadewi
}

\begin{abstract}
Person with disabilities has different needs than normal individuals. This difference causes limitations in movement and orientation. As a designer, of course in creating facilities can be used all levels of society, so the need for special treatment in design. Part of architectural context other than buildings is open space. Open space has another function, as a circulation path can also be developed in the form of park. Benefits for people with disabilities, parks can also be a means of learning, training independence and therapeutic areas. In the case study selected location in SLB-C Lawang (tuna grahita or mental retardation), this location has a large area for the development of garden design of motor development and mental children with disabilities or called educational park. The park is divided into two zones: active and passive. The active zone consists of a children's playroom and a sensory park that trains the senses of the five senses, while the passive zone as a park to be visually enjoyed. Therapeutic activities for mental retardation are not just for healing but to practice the senses' abilities of smell, taste, touch, and listener. Initially still an open space that has not been functioned specifically. The problem in this research is how the concept of accessibility and vegetation so that facilities can be used. The objective of the study was to develop a system in parks that can be enjoyed by people with disabilities and as a means of therapy. The result of this research is a concept of ease of achievement of garden for children with disfigured attention to detail of circulation design and variety of vegetation that support the concept of sensory garden so as therapy area.
\end{abstract}

Keywords: difable, movement and orientation, SLB-C Lawang

\section{PENDAHULUAN}

Orang difabel memiliki karakteristik kebutuhan yang berbeda dari individu normal, keterbatasan fisik yang dialami dapat mengurangi tingkat mobilitas dan orientasi untuk beradaptasi dengan suatu tempat. Perlakuan khusus dalam menciptakan wadah untuk beraktivitas bagi difabel seharusnya menjadi kepekaan arsitek dengan memperhatikan detail-detailnya. Perkembangan baik fisik maupun mental dibina pada saat individu tersebut bersekolah, sehingga aspek kajian fasilitas tersebut difokuskan pada sekolah luar biasa khususnya bagi difabel.

Di Kota Malang, terdapat 50 sekolah yang memiliki layanan khusus bagi difabel namun dari pengamatan peneliti, belum memfasilitasinya dengan taman tematik. Aktivitas pada masa sekolah selain mendapatkan pelajaran, siswa juga bermain di luar ruangan kelas. Bermain juga dapat digolongkan sebagai terapi jika bersifat melatih atau menyembuhkan. Delphie (2006) mengungkapkan bahwa terapi bermain merupakan sarana untuk membantu anak khususnya bagi tuna 
grahita agar dapat berkembang baik fisik, mental, intelektual, dan sosialnya. Ramadhani (2016) dalam penelitiannya mengatakan bahwa wujud pembelajaran bisa memberikan pengalaman secara langsung, sehingga siswa dapat melihat dan memahami konsep secara pragmatis. Baskara (2011) dan Lauren (2012) juga menyebutkan bahwa bermain dilakukan dengan bebas untuk memperoleh kesenangan, keriangan, dan kegembiraan dan sarana untuk mengembangkan kemampuan sosial, kognitif, fisik dan kemampuan emosinya. Semua permainan tidak harus semua ada, namun mengacu pada keselamatan.

Aktivitas terapi mendukung banyak aktivitas membutuhkan ruangan yang cukup luas, seperti bermain, bercocok tanam, ataupun memanen. Dalam suatu perancangan diperlukan beragam zona yang mendukung kegiatan edukasi tersebut. Lokasi penelitian berada pada Sekolah Luar Biasa (SLB) Pembina Tingkat Nasional Malang Bagian C di Lawang dengan Unit Pelaksana pendidikan bagi anak-anak berkebutuhan khusus. Pemilihan lokasi berdasarkan kekhususan area tempat belajar (inklusif) dari tuna grahita, namun juga perlu dikembangkan untuk jenis ketunaan lain yang ada di SLB-C Lawang, seperti tuna netra dan tuna rungu.

Hal pokok pada suatu rancangan ruang terbuka atau taman untuk difabel adalah jenis kelengkapan detail sirkulasi dan vegetasi. Selama siswa melewati area sirkulasi dapat melatih sisi kognitif dan motorik melalui jenis pembelajaran outdoor berupa rangsangan yang dirancang sedemikian rupa. Sirkulasi tentu dirancang memudahkan orang yang melewati dengan penanda khusus dan melalui area loop atau memutar, bukan gang buntu seperti labirin yang membingungkan siswa. Di sisi lain vegetasi atau tanaman, dipilih untuk merangsang siswa melalui indera penglihatan berupa warna atau penciuman berupa aromatik sehingga melatih kepekaan. Dua jenis komponen rancangan ini diperlukan dalam penataan ruang taman. Kriteria desain taman terapeutik menurut Marcus dan Barnes (2008) adalah sebagai berikut : (a) adanya zona ruang berkumpul (sosialisasi) dan menyendiri (privasi), (b) mendukung aktivitas pengguna, (c) meminimalisasi gangguan dan keambiguan, (d) menstimulasi panca indera, (e) menciptakan komunikasi antara pengguna dan elemen desain, (f) akses yang mudah, (g) adanya ruang untuk pergerakan fisik, (h) taman bersifat alami, (i) menyediakan jarak penglihatan taman yang jelas, (j) menyediakan ketenangan dan keakraban, (k) desain yang dihasilkan jelas dan tidak abstrak.

Permasalahan dalam kajian ini adalah bagaimana konsep sirkulasi atau aksesbilitas dan vegetasi yang menunjang adanya terapi yang berupaya sebagai sarana terapi anak-anak difabel? Penelitian ini bertujuan untuk menjelaskan pentingnya unsur vegetasi dan aksesbilitas terhadap terapi anak retardasi mental pada taman edukasi di SLB-C Lawang.

\section{METODE}

Metode penjelasan pada penelitian ini menggunakan pendekatan deskriptifkualitatif dan analisisnya dengan perancangan arsitektur sesuai pola pemikiran Hakim dan Setyabudi dengan konteks arsitektur lanskap. Hakim (2002) dan Setyabudi (2016), menjelaskan bahwa metode perancangan arsitektur diawali dari penetapan proyek, studi objek, inventarisasi tapak, programing, konsep, pradesain, hingga pengembangan desain. Pada kajian ini hanya membahas hasil penelitian berupa konsep, khususnya kriteria aksesbilitas dan vegetasi. alat yang 
I. Setyawudi, W. R. Hastuningtyas dan M. N. Olo / Buana Sains Vol 17 No 1: 65 - 74

digunakan untuk analisis data menggunakan software grafis komputer yaitu sketchup 2016 dan Lumion 6.01.

\section{Metode Pengumpulan Data}

Data terbagi atas data primer dan sekunder. Data primer berupa data fisik lokasi (foto, hasil ukur dan sketsa), data hasil wawancara dengan 3 guru yang secara rasionalistik dianggap senior, serta pemetaan lokasi. Data tersebut didapatkan dari observasi lapangan dengan alat kamera, alat tulis, alat rekam dan GPS. Kegunaan data untuk analisis kualitatif berupa penentuan analisis potensi dan kendala tapak, analisis

kebutuhan ruang. Lokasi dipilih di SLB bagian C Lawang karena lahan di sekolah tersebut berpotensi diolah lebih lanjut sebagai sarana terapi siswa, sedangkan pada kondisi eksisting masih berupa lahan kosong. Batas administrasi Sekolah Luar Biasa Bagian C (Tunagrahita) Pembina Tingkat Nasional Lawang Malang yaitu sebagai berikut, (a) Sebelah Utara : berbatasan dengan lahan kosong, (b) Sebelah Selatan : berbatasan dengan pemukiman warga, (c) Sebelah Barat : berbatasan dengan lahan kosong, (d) Sebelah Timur : berbatasan dengan pemukiman warga.

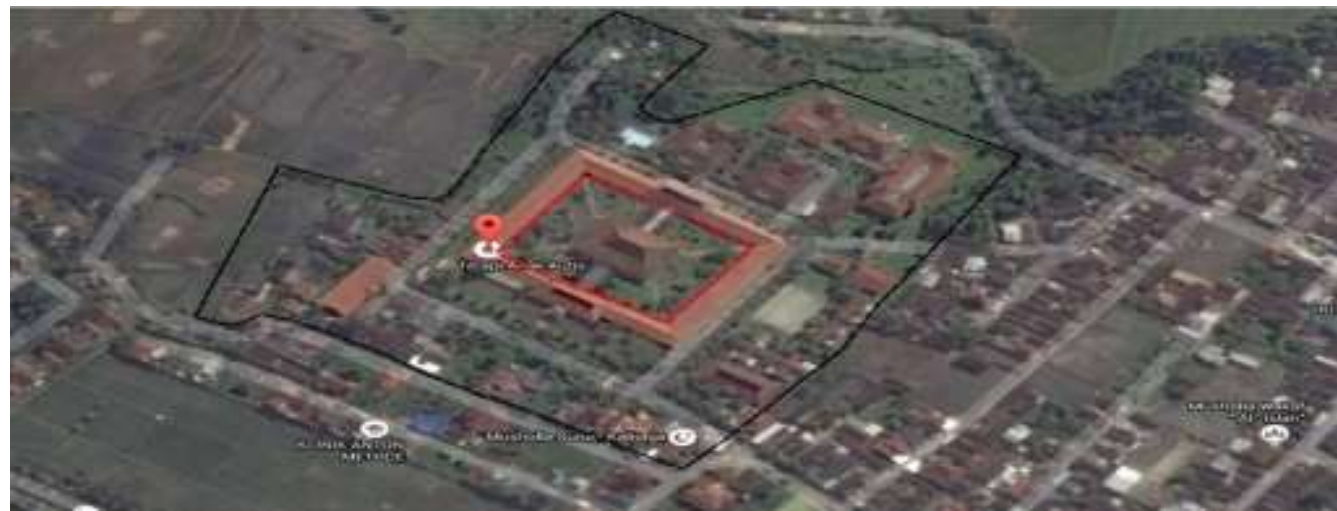

Gambar 1. Batas Administrasi SLB-C Lawang Malang (Sumber: Google Maps, 2016)

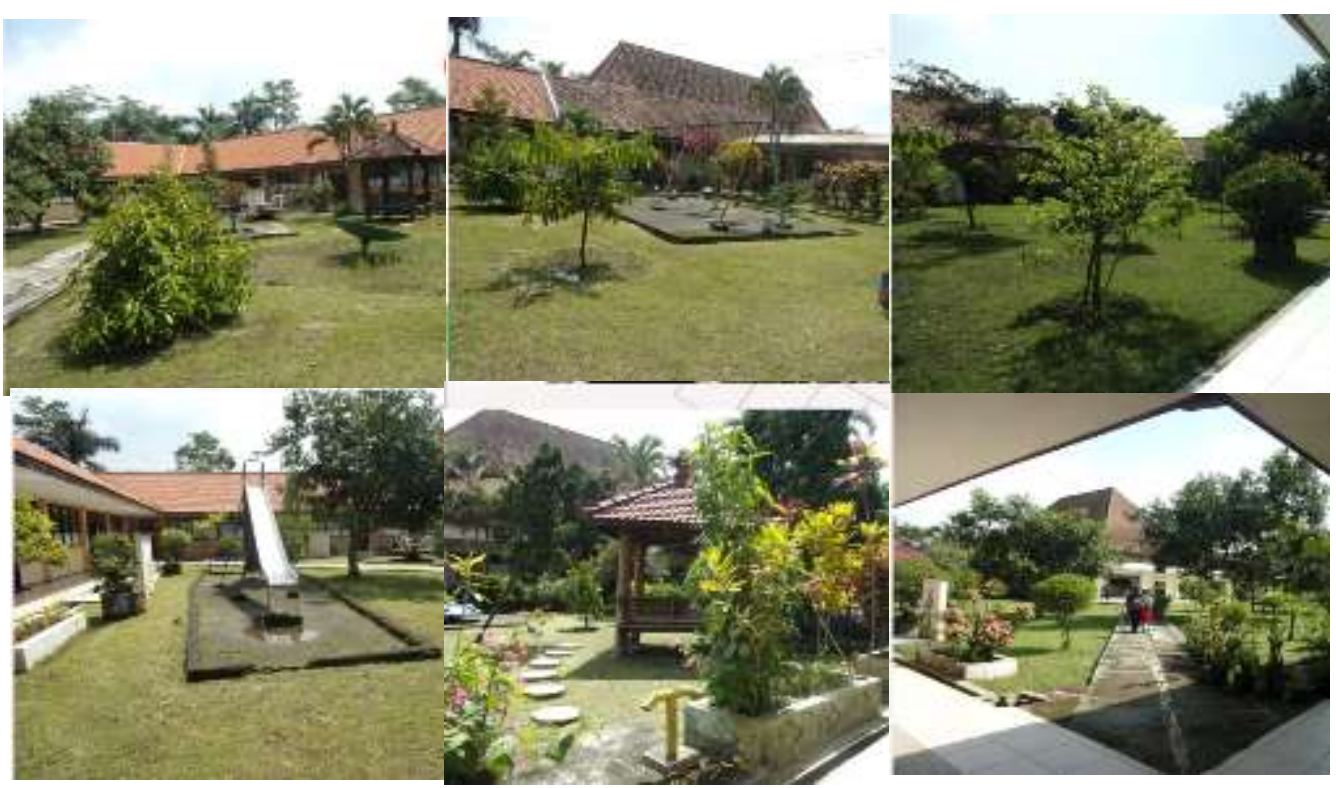

Gambar 2. Kondisi eksisting lokasi masih berupa taman pasif 


\section{Analisis dan Interpretasi}

SLB Pembina Tingkat Nasional Malang di Lawang adalah Unit Pelaksana Teknis pendidikan persekolahan yang didirikan oleh Pemerintah berdasarkan SK Mendikbud No.08/ 48/0/1986 tanggal 4 Desember 1986. Sekolah terletak didaerah strategis antara Surabaya Malang dengan luas $45.300 \mathrm{~m}^{2}$. Selain dilengkapi ruang belajar dan sarana belajar yang baik, sekolah juga dilengkapi ruang Assesment, perpustakaan, laboratorium MIPA, ruang olahraga, ruang produksi braille, arena bermain, dan asrama siswa. (sentra pklk malang). Menurut narasumber bapak Ahsan Romadlon J,. M.Pd, anak tuna grahita memiliki IQ rendah dibawah rata-rata sehingga ada yang cenderung pemalu dalam bergaul, ada yang mudah bergaul dan baik namun ada anak tuna grahita yang berprilaku agresif yakni suka memukuli temannya atau orang yang berada di dekatnya. Pak Rio dan pak Jimi juga mengungkapkan bahwa selain ada anak tuna grahita juga mencakup tuna yang lainnya yaitu tuna netra memerlukan alat bantu dalam berorientasi berupa indra pendengaran dan indra peraba seperti bunyi pantulan tongkat yang dipantulkan ke tembok, handrailing, ubin bertekstur kasar sebagai pengarah jalan, mereka mudah beradaptasi pada lingkungan yang mereka kenal namun pada lingkungan yang baru mereka perlu gambaran dari orang awas atau normal. Sebagai bahasan pentingnya aksesbilitas dan sirkulasi untuk taman terapi, berikut diuraikan hasil analisis dan konsep sebagai rekomendasinya.

\section{Aksesbilitas dan Sirkulasi \\ Eksisting pada Aksesbilitas dan Sirkulasi}

SLB Pembina memiliki ruang akses yang mudah. Ada gedung membentuk letter O' dan ada penghubung menuju gedung yang berada di tengah. Taman yang dikembangkan berada pada sisi kanan dan kiri, dan kondisi awal yang simetris. Akses juga cukup banyak sehingga siswa difabel seperti tuna grahita dan tuna rungu dapat masuk ke dalam taman, namun demikian berbeda halnya dengan tuna netra yang masih kesulitan karena tidak ada signage yang dapat dibaca. Penanda tersebut bisa berupa ubin pengarah atau lantai yang bertekstur kasar. Taman ditutupi oleh groundcover rumput, diantaranya ada jalan setapak dari beton yang dipasang dalam jarak 0.5 meter. Kondisi ini tidak nyaman untuk siswa tunanetra karena bisa terhalangi dan jatuh.

\section{Analisis Aksesbilitas dan Sirkulasi}

Tapak terdapat di bagian tengah bangunan sekolah dapat diakses melalui empat sudut sekolah yang merupakan pintu masuk (entrance) menuju ke ruang kelas sekaligus merupakan akses untuk masuk ke dalam taman. Jalan tersebut ada yang dalam kondisi baik dan ada yang memiliki kondisi retak dan berlubang yang terletak di bagian timur sekolah sehingga perlu di perbaiki. Perlu ditambahkan lantai bertekstur keras, pada jalan bagian selatan pintu masuk agar memudahkan anak tunanetra untuk mengakses ke dalam taman. Jalan setapak yang ada di dalam taman dalam keadaan rusak dapat mengakibatkan anak difabel yang melintasi jalan setapak dapat tersandung bahkan terjatuh. Pada jalan setapak tersebut belum dipasangi ubin pengarah dan tanaman pembatas di pinggir jalan setapak sehingga anak tunanetra merasa kurang nyaman jika berjalan di dalam taman tersebut oleh sebab itu perlu dipasang ubin pengarah, tanaman pembatas berfungsi sebagai pembatas agar diketahui batas atau lebar jalan setapak yang dilintasi.Berdasarkan analisis, diperlukan penanda berupa (1) ubin pengarah, (2) tanaman pembatas, dan (3) perbaikan material. 


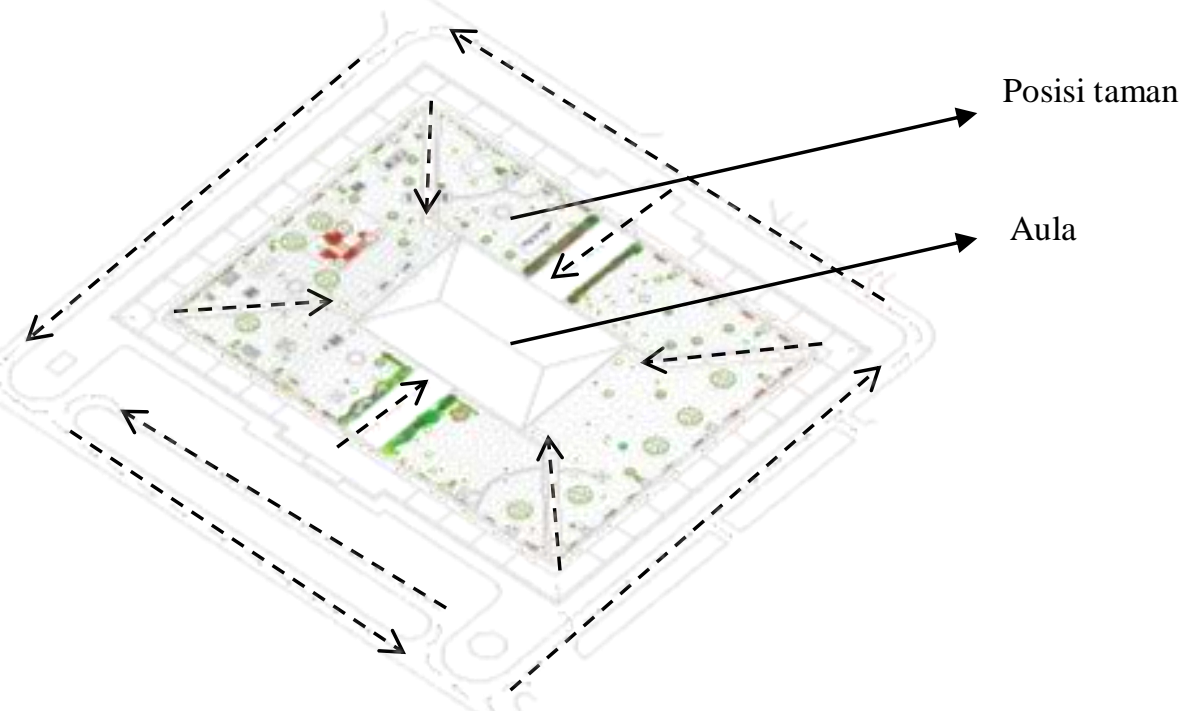

Gambar 3. konsep aksesbilitas dan sirkulasi tapak

\section{Vegetasi}

\section{Eksisting pada Vegetasi}

Vegetasi atau tanaman merupakan salah satu faktor penting dalam perancangan lanskap. Vegetasi yang terdapat di dalam taman SLB terdiri atas beberapa strata yaitu pohon, semak, border, dan groundcover yang ditanam dengan tujuan agar tanaman tersebut berfungsi sebagai peneduh, tanaman pembatas (border) dan sebagai penambah nilai estetika dalam taman. Adapun vegetasi eksistingnya adalah Mangga (Mangifera indica) 2 pohon, Nangka (Artocarpus heterophyllus) 2 pohon, Rambutan (Nephelium lappaceum) 3 pohon, Jambu biji (Psidium-guajava) 4 pohon, Klengkeng (Dimocarpus longan) 2 pohon, Cemara (Casuarina Equisetifolia) 4 pohon, Belimbing (Averrhoa carambola) 4 pohon, Sirsak (Annona muricata) 2 pohon, Alpokat (Persea americana) 2 pohon, Sawo Kecik (Manilkara kauki) 1 pohon, Melinjo (Gnetum gnemon) 1 pohon, Liliparis (Chlorophytum sp) 20 tanaman, Bayam Bayaman (Amaranthus Tri Color L.) 20 tanaman, Iris Kuning (iris flourentina L.) 30 tanaman, Bromelia (bromelia sp) 25 tanaman, krokot (Althernantera) 20 tanaman, Opipogon Putih (Ophiopogon japonicus kyoto dwartf) 20 tanaman, Taiwan Beauty (cuphea byssopifolia) 10 tanaman, Sambang Darah (Excoecaria-cochinchinensis), Rumput Gajah Mini (Axonopus compresus dwarft), Pucuk Merah (oleina) 10 tanaman, Euphorbia (Euphorbia milii rose of nothern city) 25 tanaman, Hanjuang Merah (Cordyline Terminalis) 10 tanaman, dan masih banyak jenis tanaman lainnya.

Kondisi awal taman sudah menunjukkan terawat, terlihat rapi, bersih namun masih ada tanaman berbahaya, sehingga perlu penataan ulang sesuai tematik taman edukatif yang tidak hanya dinikmati secara visual namun juga memberikan efek healing bagi pengguna dan terjamin keamanannya.

\section{Analisis Vegetasi}

Menanggapi kebutuhan tujuan penanaman vegetasi yang beragam, yaitu (1) sebagai sarana terapi, seperti aromatik dan warna, seperti lavender, (2) tanaman pembatas, contohnya penitian, (3) tanaman yang tidak membahayakan (menjauhi tanaman kaktus dan euphorbia), (4) tanaman yang tidak merusak perkerasan. Penataan vegetasi 
perlu dipertahankan agar tidak menghilangkan fungsi dari masingmasing vegetasi tersebut dan perlu dilakukan penyulaman tanaman atau

mengganti tanaman yang sudah mati agar dapat memperbaiki iklim mikro didalam tapak.

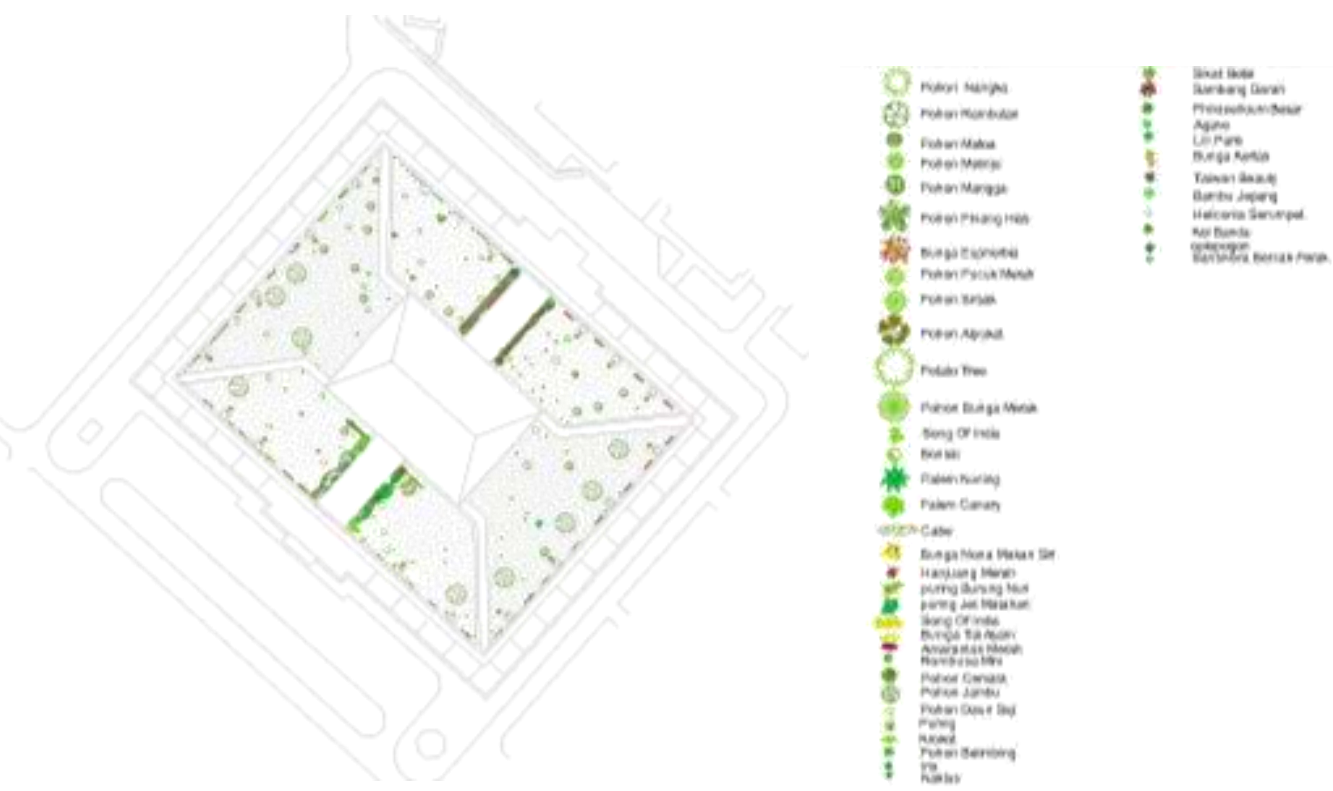

Gambar 4. konsep vegetasi

\section{Konsep Rancangan}

(1) Konsep Filosofis, berasal dari filosofi kehidupan metamorfosis ulat menuju kupu-kupu. Analoginya dari perubahan wujud. Ulat dapat diartikan sebagai hidup yang jauh dari arti kesempurnaan, sedangkan kupu-kupu adalah perubahan akhirnya. Siswa difabel yang masih belajar di SLB dapat dimetaforakan perubahan bentuk ulat menjadi kupu-kupu, yang menjalani pembelajaran dan menerima terapi untuk menuju kehidupan yang lebih baik. Proses waktu belajar seperti perubahan kepompong. Konsep filosofi dekat dengan konsep bentuk, karena filosofi yang dibuat dalam bentuk fisik. Maka bentuk dasarnya menggunakan pola corak kupu-kupu sebagai pesan yang dienkripsi. Memang dalam mengartikannya perlu penalaran dan pengalaman kontemplasi ruang.

(2) Konsep Bentuk, bentukan dari model sayap kupu-kupu yang dimodifikasi dengan lingkaran sehingga membentuk tapak yang sesuai. Pola desain ini diharapkan bisa membuat tapak lebih terlihat indah dan lebih mempermudah pengguna tapak dan tidak membuat pengguna tapak merasa bosan dan jenuh ketika masuk kedalam tapak

(3) Konsep ruang, dibagi berdasarkan jenis ruang yang dipakai oleh pengguna beserta hubungan antar ruang.

a. Ruang penerima, berupa gazebo dan papan nama

b. Ruang aktif, terdapat kegiatan yang mengutamakan gerakan aktif di dalam taman seperti bermain ayunan, bermain 
jungkat-jungkit, pelosotan, dan beberapa permainan anak lainnya.

c. Ruang pasif, dibuat untuk belajar yang melibatkan indra pada anak seperti pendengaran, penciuman, peraba dan penglihatan namun tidak banyak melakukan aktivitas fisik. Contohnya adalah bangku taman , pergola, alat musik gendang dari bahan pelastik, calung, planter box, tempat sampah, penerangan.

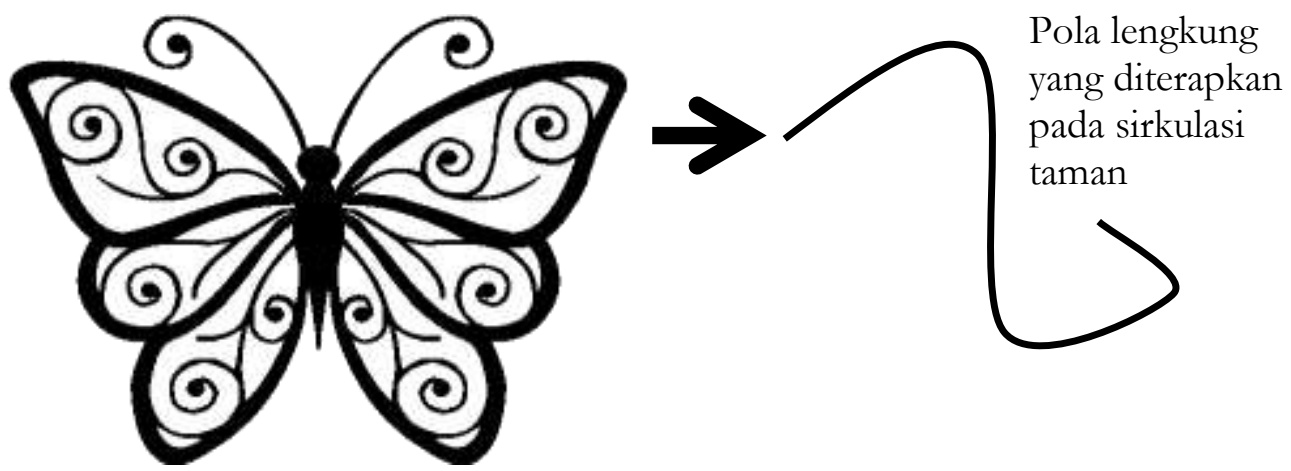

Gambar 6. Contoh fasilitas yang masuk dalam ruang untuk difabel

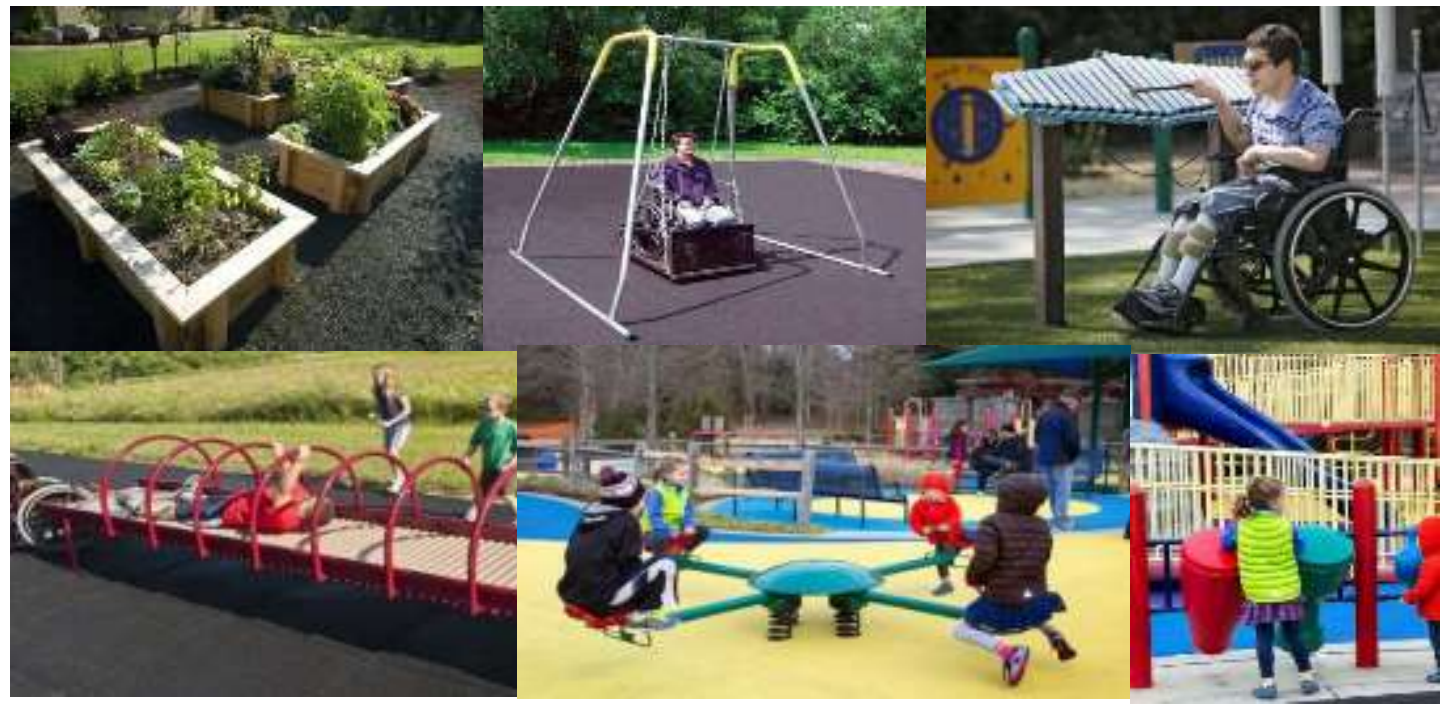

Gambar 5. Pola lengkung siluet dari bentuk kupu-kupu

(4) Konsep Sirkulasi, masih berhubungan dengan pemikiran Marcus dan Barnes (2008) yang (a) mendukung aktivitas pengguna, (b) pola sirkulasi jelas tidak ambigu, (c) menstimulasi panca indera, (d) menciptakan komunikasi antar pengguna, (e) dan akses yang mudah. Sirkulasi dapat mendukung aktivitas karena memperdekat jarak agar tidak memutar. Pola sirkulasi tegas, ada zona tengah yang terdapat ubin penanda ataupun handrail di pinggir sirkulasi. Jarak lebar sirkulasi adalah 2 meter sehinga nyaman bagi orang berpapasan dan pada titik tertentu ada daerah berkumpul sehingga tercipta komunikasi. Pengaruh pola lingkar kupu-kupu hanya sebagai variasi sebab pola melingkar adalah dinamis dan tidak membuat orang lelah. 
(5) Konsep Vegetasi, menurut Marcus dan Barnes (2008), taman bersifat alami dan menyediakan ketenangan dan keakraban. Hal tersebut bisa diperoleh dengan pemilihan jenis vegetasi yang sesuai. Kriteria pemilihannya adalah (1) aman bagi orang difabel, (2) berfungsi tertentu pada tapak, seperti peneduh, pengarah, pembatas dan penutup tanah, (3) berfungsi penambah estetika yaitu pola tanam, warna, dan aroma. Contoh aplikasi tanaman sebagai berikut. Tanaman tidak disarankan menggunakan jenis tanaman yang berduri dan beracun karena dapat membahayakan, diantaranya dadap merah (Eritryna cristagali) dan Flamboyan (Delonix regia) - dahan mudah patah dan akar merusak perkerasan, sengon (Albiria $s p$.), tajuk padat, dahan mudah patah dan tumbang karena angin. Tanaman pohon/semak/herba berduri dan bergetah gatal seperti keluarga kamboja (Plumeria sp.), cocor bebek, euphorbia, dan Rhodendron, Keluarga bambu tidak disarankan untuk ditanam karena pemeliharaan yang sulit, bromelia dan agave serta draseina sebaiknya tidak digunakan, banyak jenis dari getahnya yang mengakibatkan iritasi dan alergi. Adapun keseluruhan tanaman yang direkomendasikan antara lain :

\begin{tabular}{|c|c|c|c|}
\hline No & $\begin{array}{l}\text { Nama lokal \& } \\
\text { jumlahnya }\end{array}$ & Nama latin & Keterangan \\
\hline A. & Kelompok Pohon & & \\
\hline 1 & $\begin{array}{l}\text { Pohon } \\
\text { bauhinia/bunga } \\
\text { kupu-kupu ( } 5 \text { ) }\end{array}$ & Baubinia sp. & $\begin{array}{l}\text { Pohon berbunga dengan helaian daun seperti kupu-kupu, } \\
\text { ditanam untuk tanaman tepi jalan }\end{array}$ \\
\hline 2. & Pohon merak (5) & Caesalpinia sp. & Pohon berbunga, ditanam sebagai aksentuasi \\
\hline 3. & Pohon sikat botol (4) & Calistemon sp. & $\begin{array}{l}\text { Tanaman dengan bentuk tajuk columnar berbunga merah, } \\
\text { ditanam sebagai tanaman pengarah jalan }\end{array}$ \\
\hline 4. & Pohon Jati mas (4) & Cordia sebestena & $\begin{array}{l}\text { Pohon tajuk membulat berdaun lebar dan berbunga, } \\
\text { dapat ditanam di tepi jalan }\end{array}$ \\
\hline 5. & Pohon kasia (4) & Cassia sp. & $\begin{array}{l}\text { Pohon dengan tajuk memayung berbunga. Ditanam untuk } \\
\text { memberi naungan. }\end{array}$ \\
\hline 6. & $\begin{array}{l}\text { Pohon biola cantik } \\
\text { (4) }\end{array}$ & Ficus byrata & $\begin{array}{l}\text { Tanaman eksotik keluarga beringin berdaun lebar, untuk } \\
\text { memberi naungan. }\end{array}$ \\
\hline 7. & Pohon tabebuia (2) & Tabebuia crisantha & $\begin{array}{l}\text { Tanaman eksotik columnar berbunga kuning dan efektif } \\
\text { menyerap polutan, ditanam untuk aksentuasi/pemanis } \\
\text { area. }\end{array}$ \\
\hline 8. & Pohon batavia (4) & Jatropa sp. & Pohon rendah berbunga merah serempak \\
\hline 9. & $\begin{array}{l}\text { Pohon kerai payung } \\
\text { (4) }\end{array}$ & Filicium decipiens & Pohon sedang bertauk membulat, untuk naungan \\
\hline 10. & Pohon bungur (4) & Lagerstromia spesiosa & $\begin{array}{l}\text { Pohon berkayu keras berbunga ungu sebagai naungan dan } \\
\text { aksentuasi. }\end{array}$ \\
\hline 11. & Pohon kayu putih (4) & Pimenta dioica & $\begin{array}{l}\text { Pohon dengan daun wangi, ditanam sebagai aksentuasi } \\
\text { taman }\end{array}$ \\
\hline 12. & $\begin{array}{l}\text { Pohon Spatodea/ } \\
\text { African tulip (4) }\end{array}$ & Spatodea campunulata & $\begin{array}{l}\text { Pohon tinggi seperti bunga tulip orange bartajuk } \\
\text { membulat }\end{array}$ \\
\hline B. & \multicolumn{3}{|c|}{ Kelompok Semak/ Herba } \\
\hline 13. & Famili aglonema (20) & Aglonema sp. & Tanaman naungan berdaun lebar bercorak \\
\hline 14. & Gardenia (20) & Gardenia augusta & Tanaman berbunga putih yang harum \\
\hline 15. & $\begin{array}{l}\text { Heliconia/jahe-jahean } \\
\text { (10) }\end{array}$ & Heliconia sp. & $\begin{array}{l}\text { Keluarga heliconia berkelompok berdaun lebar dengan } \\
\text { bunga ekesorik serempak. }\end{array}$ \\
\hline 16. & Spatipilum (20) & Spathipilum sp. & Beberapa jenis berbuga harum \\
\hline 17. & Famili diffenbachia & Diffenbachia sp. & Tanaman berdaun lebar bercorak \\
\hline 18. & Soka (4) & Ixora sp. & $\begin{array}{l}\text { Bunganya kecil serempak berwarna warni, beberapa } \\
\text { bermahkota bulat/ hortensia. }\end{array}$ \\
\hline 19. & Walisongo (20) & Manihot esculenta & $\begin{array}{l}\text { Tanaman daun majemuk. Beberapa merupakan variegate } \\
\text { bercorak kuning }\end{array}$ \\
\hline 20. & Lollipop (20) & Pachystachys lutea & $\begin{array}{l}\text { Tanaman dengan bunga kuning meyerupai kumpulan lilin } \\
\text { serempak. }\end{array}$ \\
\hline 21. & Melati costa (20) & Psuderanthemum sp. & $\begin{array}{l}\text { Tanaman berdaun kuning kehijauan dengan bunga putih } \\
\text { yang harum }\end{array}$ \\
\hline C. & \multicolumn{3}{|c|}{ Kelompok Ground Cover } \\
\hline 22. & $\begin{array}{l}\text { Kriminil/joyweed } \\
(20)\end{array}$ & Althenentera tenella & $\begin{array}{l}\text { Tanaman cahaya penuh berdaun lembur bercorak hijau } \\
\text { keputihan }\end{array}$ \\
\hline 23. & Arachis (20) & Arachis pintoi & Tanaman keluarga kacang-kacangan berbunga kuning \\
\hline 24. & Spider lily (40) & Clorophytum comosum & $\begin{array}{l}\text { Tanaman berhelai tipis menjuntai dengan warna hijau } \\
\text { strip putih }\end{array}$ \\
\hline 25. & Taiwan beauty (40) & Cuphea byssopifolia & Tanaman berdaun kecil dengan bunga ungu serempak \\
\hline 26. & Tapak dara (20) & Impatiens sp. & Tanaman suculen berbunga merah serempak \\
\hline 27. & Iris $(40)$ & Neomarica sp. & Tanaman berhelai rumput ilalang berbunga indah \\
\hline 28. & Jaburan (40) & Ophiopoghon jaburan & $\begin{array}{l}\text { Tanaman berhelai rumput tipis berwarna hijau atau } \\
\text { berstrip putih }\end{array}$ \\
\hline 29. & Wedelia $(40)$ & We delia trilobata & Tanaman berdaun padat dan berbunga aster kuning. \\
\hline D. & \multicolumn{3}{|c|}{ Kelompok Tanaman Merambat } \\
\hline 30. & Alamanda (40) & Allamanda chatartica & Tanaman berdaun tebal berbunga terompet kuning \\
\hline 31. & Stephanot (40) & Marsdenia floribunda & Tanaman berdaun tebal berbunga putih aster kompak \\
\hline 32. & Red jade (40) & Mucuna novoguineensis & Tanaman dengan tandan bunga warna merah kompak \\
\hline 33. & Passiflora (40) & Passiflora sp. & Berbunga passion aster merah atau bermahkota sangkar \\
\hline
\end{tabular}


I. Setyawudi, W. R. Hastuningtyas dan M. N. Olo / Buana Sains Vol 17 No 1: 65 - 74
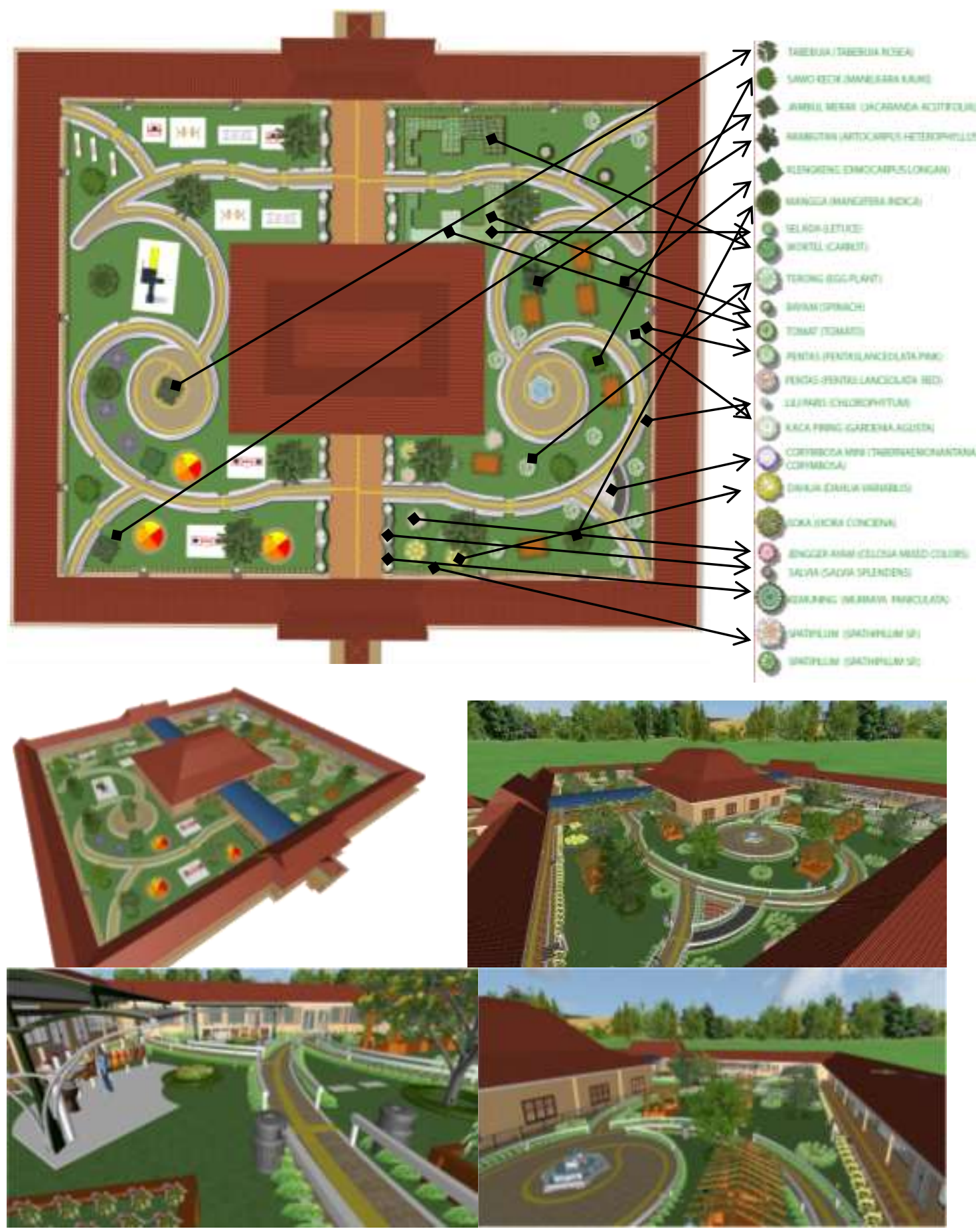

Gambar 7. Contoh planting plan dan perspektif untuk menunjukkan posisi vegetasi dan sirkulasi

Adapun rangkaian konsep sirkulasi dan vegetasi di atas jika diterjemahkan dalam bahasa arsitektur menghasilkan pradesain seperti blockplan dan gambar perspektif berikut, Temuan pada penelitian ini berupa konsep sebagai berikut, (1) aksesbilitas mencakup pola sirkulasi, dapat disesuaikan dengan tema dan 
konsep yang dikembangkan, seperti penggunaan pola lingkar kupu-kupu yang memiliki metafora tertentu, (2) pola pencapaian harus didasarkan pada kemudahan akses bagi difabel terutama siswa tuna netra, yang memiliki keterbatasan tinggi, (3) sirkulasi memiliki ubin pengarah yang memudahkan akses, (4) aksesbilitas dapat menghubungkan antar zonasi, seperti zona duduk-duduk dan ruang gerak aktif, (5) perbedaan ketinggian permukaan dapat diatasi dengan kemiringan tertentu tidak lebih dari $5^{0}$, (6) pola penanaman disesuaikan dengan fungsi vegetasi, (7) vegetasi dapat berfungsi sebagai border sehingga orang difabel tidak akan takut jatuh ataupun tersandung, (8) vegetasi dapat berfungsi menciptakan efek healing sebagai terapi yang membantu melatih pancaindera sehingga lebih sensitif, seperti aroma dan warna.

\section{Kesimpulan}

Penelitian ini ditemukan bahwa
adanya konsep taman yang mementingkan segi aksesbilitas dan vegetasi dengan menambahkan dari pendapat sebelumnya yaitu taman yang mewadahi aktivitas normal, desain taman yang difokuskan pada stimulus panca indera, pembedaan tata ruang menjadi zona penerima, interaksi sosial, ruang terapi serta pemilihan vegetasi. Peneliti hanya membatasi ide tersebut hingga konsep atau rekomendasi untuk desain sehingga pada penelitian selanjutnya sampai ke tahap desain, dan penerapan desain tersebut sehingga dapat diketahui nilai efektivitasnya terhadap tingkat penggunaan oleh siswa difabel.

\section{Daftar Pustaka}

Baskara, M. (2011). Prinsip Pengendalian Perancangan Taman Bermain Anak di Ruang Publik. Jurnal Lanskap Indonesia, 3 (1), pp. 27-34.

Delphie, B. 2006. Pembelajaran Anak Berkebutuban Khusus. Bandung: Refika Aditama disitir oleh Bau Dkk [PKM-P] Model Taman Pembelajaran Untuk Anak-Anak Tunanetra Di Kota Malang. Malang Universitas Tribhuwana Tunggadewi Malang

Hakim, R. (2012). Komponen Perancangan Arsitektur Lansekap : Prinsip-Unsur dan Aplikasi Desain. Jakarta : PT. Bumi Aksara.

Lauren, G.M. (2012). Desain Taman Lingkungan untuk. Anak Usia Sekolah Dasar Di Cluster Callysta Permata, Perumahan Permata Bintaro, Tangerang Selatan. (online) http://repository.ipb.ac.id/handle/12345 6789/61159. diakses 16 februari 2017.

Marcus, CC dan Barnes, M. (2008). Healing Gardens: Therapeutic Benefits and Design Recommendations. Di dalam: Kreitzer MJ. Healing by Design: Healing Garden and Therapeutic Landscapes. InformeDesign : Implications, 02 (10): 1-6.

Ramadhani, W.S. (2016). Penerapan Pembelajaran Outdoor Learning Process (OLP) Melalui Pemanfaatan Taman Sekolah Sebagai Sumber Belajar Materi Klasifikasi Tumbuhan Untuk Meningkatkan Hasil Belajar Siswa SMP. Jurnal Pendidikan Sains, 4 (3), pp. 1-7.

Setyabudi, I. (2016). Elemen dan Proses Desain Arsitektur Lanskap Taman Rumah Tinggal. Malang : CV. Dream Litera Buana. 